\title{
12 Remixes
}

\author{
MICHAEL SZPAKOWSKI
}

Independent artist and scholar

\section{ABSTRACT}

The text below has its origins in a 2012 sound/image/conceptual art work, by the present author, entitled 12 Remixes. ${ }^{1}$

Every month, throughout the year August 2011 - July 2012, I entered, under the pseudonym Mickiewicz, an online remix competition (where a record company provides the individual instrumental recordings, known as the stems, of a track by an artist they are promoting, and solicits remixes) and posted each entry online to a blog, both as annotated sound files and, later, as music videos.

12 Remixes and various component pieces of it have since been repeatedly shown in various exhibitions and screenings around the world.

Both sound and video pieces involved the addition of appropriated material to the manipulated original files as well as, importantly, a willing surrender to the unconscious, to automatic operations and an active espousal of stylistic incongruity.

My commitment to this approach of art-making, where the artist to a greater or lesser extent eschews conscious direct control over their materials and processes, ceding this to chance juxtapositions, algorithmic/formal procedures and also simply yielding readily to the unconscious, follows my understanding of what it means to "remix", which, for me, connects strongly to the idea of oracle, to the Jewish name/number tradition epitomised by Abulafia and more recently to the cut-ups of Gysin and Burroughs.

Shortly after I made 12 remixes it was discussed at length by the critic Edward Picot in a piece in the online journal $\mathrm{H} / \mathrm{Z}^{2}$

In the piece of writing that follows I complete a circle, and investigate my 'sense' of remix, by myself remixing Picot's text, using methodologies similar or analogous to those of my original project - in particular, cut-up, alphabetisation and reordering, and the repeated use of automatic translation from languages with radically different grammars. It is curious to me how much relevant sense of meaning is both retained and generated by this process - both in the found, 'oracular' sense but also by the expanded semantic clouds generated by serial translation. 
I want to absolutely be clear. What follows this introductory note is intended first and foremost as a literary text.

As author/maker/enabler faced with a choice between solutions that seemed to me beautiful and something less so, I always opted for the elegant, the evocative, the humorous and the-yesbeautiful.

\section{What's it for?-What is literature for?}

The justification for its submission to, and appearance in, an academic journal seems to me to be twofold. Firstly, it is an unconventional, but nonetheless valid, response to the original call for papers, which was itself literary in tone, citing Borges, and directed towards the use of remix in contexts other than the original musical one. Secondly, it is experimental in the genuine sense of the word (although the analogy with scientific process is not complete since it was an experiment conducted without defined hypotheses). Nonetheless this experiment yields results which might be useful in approaching some key questions in the philosophy of language. What happens when certain operations are performed on a text as part of this process of remix? What can we learn from the result about questions of style, genre and meaning? Indeed, how can we use the word meaning to characterize aspects of both discursive/scientific texts and of literary works too?

This abstract is already too long and neither is this the place to answer those questions, which might provide some material for analysis in a more conventional paper, by someone else, at some point in the future.

\section{Remixes}

Video artist and musician Michael Szpakowski participates in a remix every month and edits his mix on his website (some with accompanying videos) because modern life itself has become more complicated and goes on to a point where a lot of listeners might find themselves wishing it would stop. This article is not easy to publish, its content is unique, culturally diverse and even time consuming.

Szpakowski's remixes dispense with almost everything. The results are often startling. We see the artist as a medium, who advocates the use of cutting and bending techniques in literature. The artist is bound to be more complicated than the chiming melody from Tchaikovsky's Sugar Plum Fairy but the piece would still have a purpose and meaning of its own beyond them, as a peal of bells has its own purpose. Perhaps most artists see themselves in remixing their work by peers, not inspiration from art, art history or other cultures. The "I" in those voices begins with some variation of identity. It grows rapidly, becomes background noise and is very big and angry, making it difficult to listen. Digital media is often associated with the different components of mutuality. It is important to see a remix - White House and archival material, Japan's movies, screenshots of Little Red Riding Hood, square American kids dancing, boxing gloves, clay materials, great literature and mixed colour pixels. From this moment, the images of the desert, and the middle of the city catch up on Google. 
To this he adds "Usually the voice has zero items to discover!" and the vocals have slowed down from annoying chipmunk to the burial of Darth Vader; the bass line has slowed down too, from the prefabricated trophy shaker to the sinister things in the ground. In the upper space, the echo keyboard notes float and pulsate like a glowing jellyfish. The effect of the lyrics is mournful, the reconstituted sounds are dirtier, fuzzier, more textured, and the rhythms are more complex. Words come from mashup tweets; we feel firstly that great leaders and orators are being mocked, and then that identity itself is being called into question, when life is characterized not only by "diversity and complexity," but also by information overload. Therefore, one way to understand Szpakowski remixes is to identify what the remix is. From the project he said, "I am 54 year old music consumer is still a little bit better developer try zero. Viewed from the perspective of modernism, postmodernist and digital modern aesthetics. Yes, I'm looking at the sound of a sound the artist and poet Brion Gysin borrowed." The voice started at BBC in 1950. "I" in the text is seen in five of the possible worlds that the idea is to organize.

"My cat, who was arrested," is, for example, a good result and "Laundry Speak Heck!" in Colonel Red's exciting words in the Middle Eastern European languages, with or without a statement at the end of the day. It's a good idea that these words, which means that they're very difficult:

"I know that you know why I'm here Danceflo'/ We can have our sandwiches ... / I can spit, I am a burger / Butter girl with thighs/ Light propagation ..."

Let the beginning be of great importance, zero the number of music videos. This indicates the visual realization attached is in sync with the beat of the music by covering the main feature of his work. The effect of the wall again, according to the three-dimensional feeling, must be destroyed by the fact that it is significantly less than that of the product. In addition, the audience is not interested in who is considering the stage and accepting supply; there is the developer and process and again, comedy is smarter than the mouse. It is being replaced by something difficult to determine.

Further, the remix is often stunning and it was good and dusty. And angry, often feeling more than his old original. This, indeed, I see. However the structure is in line with similar growth patterns. Program description is used, until it starts to sound very loud fast-persistent. As it is, they are trying, when compared at the end to the original memory, and the difference is only a blueprint - the "I Am I," from the music library in the US based on the original work by a third party. To achieve this effect turns out to be very provocatura and something special. There are tons of different temperatures, the intellectual and innovations but there is only one plain argument. Speaking of language, intentionality, machos and boundaries are always messy.

As stated above, this remix (" 1 ") is the voice of one of Staines Gysin traffic. An example: the American voice that says "OK good and stand clear, the door is closed!" "Well, stand clear," in the "good" conversation is recorded as William Burroughs. And on the first Burroughs it's the latter of them, which may be eaten by Gysin. Artisans experience trading Gysin intact. To that end, he said "Yes? Okay" and "closed the door" as well as a famous letter.

Szpakowski is not even proud of the series. He spends his time building remixes because he thinks it's something. Interestingly, he works as a musician. 
Szpakowski's overwhelming power provides almost everything except the rhythm section. The rhythm section is very slow and the new footwear has a terrifying elephant quality.

Szpakowski's remix is different.

Szpakowski's remixes are never mathematical or symbolic sequences, but they certainly provide evidence of his motivation for various logical advances.

One of the best of these is the "good principle is good" video. The video generates a text version of the word on a large screen when you listen to it. The original soundtrack is a funk/soul song with horn and female production. The original song was an over-the-top rapper. It became faster, faster and more professional, but inspired by work. Original tracks often focus on musical style aspects with a limited range of themes and are often drawn boldly to the audience. Dance, they want to feel sex. Or trying to put them in the box. Frank Friend's "Trying to Awaken," Trojan's "Beer Atlas", and Mimi Page's "Phrases and Sport" are all based on bad faith. The project is intentionally outside its own "comfort zone". In other words Remix is looking for a face to face answer.

The results are always amazing.

What the viewer can use is less compared to the original, but the collaboration with Gysin provides insights into the dynamic management of the " 12 memories" per subject. To me, this is a good idea for fine lines, all five shapes, like the top of the head. Game situations: it's like "normal" verses, like the sound of an arrow. The songs are "smooth", their structure and length are far, not to mention some of the audience's thoughts on the content. Even if it comes to mind but the curiosity to keep the various kinds of rules flowing continuously. The recording process is the same: he uses the input counters and switches the speakers. He performs the latest rotor assembly and then adds or refines these objects until a definite result is achieved. Also, you don't care what your audience is up against or the content: it only focuses on language and functionality. This does not mean "Who I am" doesn't matter. Delivered in big rings, when it does start to come, we keep the cast out of the main house like Citizen Kane, Mussolini or Hitler. But verbal criticism may mean they don't make a deal. At first it is known that the owner is a journalist, as well as their identification, and they are sceptical. However, as students, we think that these answers should be an exaggeration. They were not made in the first place, and if we did not try them, some thoughts on the matter might come out. It has a meaning behind it because it is the cause of vibration whether you like the words or not.

Interest in change and change itself can be combined with unstable phases and refinements of mathematical concepts and developments in the new world, with newcomers thinking about asking questions or preparing for the basics. And creating a graphic design but following the example presented it can be combined with a more traditional look. At the same time, it is important for photographers who use computers and images to see this section contains five words that can apply to those who want to be disciplined. We have extensive experience in the digital and technological environment. Prior to the digital age, adjusting the frequency often could not be heard on the radio, with vinyl powder in many nearby aircraft. But by the end of the Szpakowski's 'music system remix of planning,' construction is not consistent with a broader understanding of certain divisions. 
An example is "Cat". With the cat, you will hear frequently asked unnecessary questions about cat care and start with a useless Facebook message. Replace the sequence number with "funign funign funign". Shocking, angry, forced. The effect of the song is no longer deep, sad, sad, useless. The end result is as beautiful as it is biased, but otherwise beautiful. The sensation of road has completely changed and the field and geometry have changed. We realize that we are in a darker and wider place. Synthetic voices first announce the purchase of cats and then unwanted questions about cats and cats begin. "Has your cat tested your style?", "Hair?", "What is the most funny and painful story of your cat?" Breaking slowly compared to other topics, followed by "Let's become a great Facebook brand!" Getting started, you first have your cats and organizations in business, and then start asking some quick and pointed questions about cat and cat care. "Is your cat trying to add hair?"; "What is the story of a beautiful and painful baby?" Most music videos with videos produced by Szpakowski show similar features-watch a video clip from an adult that can help young people with mental health problems (possibly a foster cat). Scott Highlander is dark. Inflatable flu shots. The situation is sensitive to the viewer. But there is also a good time in the video "I am a cat". In the old-and-white movie, the boy sitting up begins to move from side to side during the music.

No change is needed to work. He says: "I haven't played (or haven't done it in 20 years). There's a huge difference in how you feel about popular music but it's not always easy when you press your finger." According to Szpakowski, the figures are from "available" sites on the Internet, as many companies believe. Some places may be easy, but there are always problems interpreting it - usually they vote in a foreign language. First we like the ads and then and only then we sort their identity. It likes, jokes, jokes, surprises or pulling a number in and eventually disappearing. At the end of the street the piano is decorated with string.

The process of designing and organizing objects and entities can be related to new research based on mathematical rules. What creates works of art? As Bell's example shows, it has a lot to do with old-fashioned clusters. At one point, it was important for artists to use computers and swords. They are beautiful with stained glass windows, which reduces your confidence. These two-person relationships show a connection between the gene of Rek Shakuki and the modern artist. The tradition is closely associated with mashups. Mashup can keep up with their ancestors in packaging and folding as well as collages, DIY, labels and other techniques without knowing about game control. Recall Zanar's Unique Composition. With Zanar it is not only the ancient tradition of artists found in the quest for independence, it is a collective experience that does not reflect the present. Instead, ideas and images come from different perspectives, times and traditions.

Szpakowski's diet is no longer unique to his family. But it does provide examples for sound and transformative change. This can also lead to some situations that are not well understood but also contribute to a longer and more lonely life. As mentioned earlier, there are differences when compared with the above methods, which are not known to humans. But the fact is that they are not planning to take the same steps when making music. For example, if we look at the traditional way of moving dogs when we talk about singers it is because Szpakowski doesn't. Another example is "The Moon in the Snow" and "The Blind Side," which refer to Julian The Slow (he's the medium on Bon Iver's original tour). From the perspective of the progress of the play, it is clear that the piano and violin, along with the woman, heard the male voice. At the end of the 
song, we were like walking. It has a stomach. Szpakowski, on the other hand, is cheerful and is part of the cast. He cut and changed the tape of the female voice to create a different, haiku-like, simple poem, and he also changed his original language with a Japanese-speaking woman. The result is the same as in the next section. But with a variety of straps it's very hard, friendly and a little talkative and fun. Often a word is a word, though sometimes a number speaks a different language. What started out as happiness, confusion and desire go or into the digital world and at the far end of the package is the tower, extension and the rope.

A good digital artist, whatever the personality or style, can do more than just raise the sound and create an image.

\section{ACKNOWLEDGEMENTS}

My warmest thanks to Edward Picot for his permission to work with and on his original text here.

\section{ENDNOTES}

1. Michael Szpakowski (posting as Mickiewicz), 12 Remixes (blog), twelve posts from August 15, 2011 at 9:17 pm to July 1, 2012 at 11:24 am, http://www.michaelszpakowski.org/mickiewicz/ 2. Edward Picot MIXING IT: 12 REMIXES BY MICHAEL SZPAKOWSKI, H/Z \#19 (2014), http://www.hz-journal.org/n19/picot.html

\section{AUTHOR BIO}

Michael Szpakowski is a UK based artist, composer, writer and educator. He holds a PhD by publication awarded in 2016 for his 400+ ongoing sequence of short online videos started in 2003, Scenes of Provincial Life. 